\title{
LA EMIGRACIÓN ASTURIANA EN EL PENSAMIENTO DE JOVELLANOS
}

El tema de la emigración presenta múltiples facetas que han preocupado muchas veces a las autoridades y a los estudiosos: las causas que la provocan, los bienes o los males que produce, los remedios para evitarla y hasta el tema del simple derecho a emigrar. Por otra parte, un estudio a fondo de la emigración y de la inmigración de una región pone de relieve toda la situación económica, social y cultural de esa región.

De la emigración asturiana en el siglo XviII no se sabe todavía lo suficiente ${ }^{1}$. De aquí que analizar lo que piensa Jovellanos puede servirnos para centrar un poco el problema aunque queden en el aire ciertas cuestiones importantes: estadística de la emigración, destinos de los emigrantes, significación de la riqueza que los emigrantes pasaban a Asturias.

Es lógico que Jovellanos sólo trate de la emigración de los campesinos. La de los artesanos y menestrales tenía que ser escasísima, ya que era también un grupo social bastante reducido y sin especiales motivaciones para buscar trabajo en otras partes. Sin embargo, el campesinado era el grupo social más abundante (superior al $70 \%$ a lo largo del siglo XVIII $)^{2}$, y era el que estaba sometido a mayores presiones económicas. El número de labradores propietarios era muy escaso, pues la mayor parte de la tierra cultivable pertenecía a la iglesia y a la nobleza ("los mayorazgos y los monasterios e iglesias son casi los únicos propietarios de Asturias', escribía Jovellanos), con lo que un porcentaje muy crecido de la población campesina ejercía simplemente como colono. En el Archivo Histórico Nacional (Consejos, leg. 4173) se conserva un informe del Corregidor de Oviedo de septiembre de 1769, en el que se explica la ausencia total de comerciantes en granos por el hecho de que Asturias no producía más grano que el necesario para el consumo, "por la pobreza de los labradores", ya que "todos o los más" lo eran "de caserías y haciendas ajenas" y sólo llevadores de aquellas tierras que

1 Puede verse Geografía de Asturias, dirigida por Francisco Quirós Linares, t. 4, Geografía humana, t. 3, Ayalga Ediciones, Salinas, 1983, especialmente el cap. II.

2 Todavía en 1900 el $69.76 \%$ de la población activa pertenecía al sector primario, lo que significaba más de 400000 personas (I.N.E., Censos de población y Padrón de Habitantes de 1975). 
podían darles unas cosechas que les permitieran "la anual paga de su renta y la manutención de sus familias con bastante escasez". No les quedaba, por lo tanto, a los labradores excedente alguno que vender ${ }^{3}$.

Lo primero que interesa es ver cuáles son para Jovellanos las causas de la emigración campesina. Naturalmente, la primera es la pobreza; pero esa pobreza obedecía a la situación de minifundio del campo asturiano. Don Gaspar analiza el minifundismo desde los primeros tiempos del reino de Asturias, sobre la base de una propiedad señorial y eclesiástica, que empieza pronto a extenderse hasta incluir una buena parte del territorio. Le parece que en un principio fue beneficioso para las familias de los colonos y para el cultivo de la tierra el que los propietarios permitieran dividir las suertes entre los hijos de los colonos. Pero esta costumbre, con el paso de los años, llegó a constituir un mal inmenso: el propietario seguía permitiendo la división, porque nada le iba en ello; pero el resultado estaba claro: los nuevos herederos recibían una cantidad minúscula de terreno, que no les permitía una vida digna. La consecuencia era lógica: había brazos sobrantes en el campo, y estos hombres, antes de morir de hambre, buscaban una solución, la única que, analfabetos en su mayor parte y sin ninguna preparación profesional, tenían a su alcance: emigrar a otras provincias en busca de cualquier trabajo.

Había tres tipos de emigración: el estacional, para realizar tareas agrícolas en Castilla; el permanente, a otras provincias españolas, especialmente a las grandes capitales, y fundamentalmente a Madrid, para ocuparse en trabajos no cualificados, y el que se hacía a América. El primero se verificaba una vez realizadas las duras tareas de la primavera y comienzos del verano, no significaba abandono de la tierra y aportaba pequeñas cantidades a la familia. El segundo era el más frecuente: se disminuían los brazos para trabajar, pero también se disminuían bocas, y esto era un alivio para la familia del emigrante. El tercero supongo que era poco frecuente en el siglo XviII, aunque no se dispone de datos.

Jovellanos pone el acento en un punto muy concreto: el minifundio deja a los campesinos sin ninguna posibilidad de defensa económica. Esto dice:

Lejos de haberse incorporado, se aumentó cada día la división de las suertes, y éstas se fueron subdiviendo y multiplicando. Yo he visto dividida en cinco una casería que no muchos años antes estuviera destinada a un solo labrador. Esto ha hecho muy miserable la suerte de no pocos colonos, porque todo el afán de un año no basta para dar a una familia subsistencia cómoda ni segura. Cualquiera de los comunes accidentes que causan esterilidad o disminuyen las cosechas, cualquiera contratiempo, cualquiera atraso conduce al pobre agricultor a la miseria y la ruina. De aquí las emigraciones a otras provincias; de aquí el abandono de las suertes; de

3 Cit. por Gonzalo Anes, Historia de Asturias, t. 7, Edad Moderna, t. 2, Ayalga Ediciones, Salinas, 1977, p. 170. 
aquí el desamparo de las familias y otros males sobre que no puede dejar de llorar la humanidad ${ }^{4}$.

Poco después Jovellanos llega a expresiones que no podemos olvidar hoy. Dice así:

Alguno creerá que la ilimitada multiplicación de los labradores es siempre conveniente; pero se engaña. No basta que una provincia aumente el número de sus cultivadores; es menester que estos cultivadores tengan una subsistencia cómoda, y sobre todo segura. De otro modo la menor desgracia les hará abandonar sus suertes, y este abandono será siempre perjudicial, no sólo a la familia que le hace, sino también al propietario que sufre sus consecuencias. Aun sin desgracia alguna faltará muchas veces la constancia para continuar en el cultivo, porque trabajar mucho, comer poco y vestir mal, es un estado de violencia que no puede durar ${ }^{5}$.

No estamos simplemente ante un problema de hace dos siglos, pura historia sin ningún reflejo actual, al contrario, es un problema vivo, a pesar de que hayan cambiado las circunstancias. Aunque el campesino sea ahora más sensible a su situación de desamparo y más vivo su deseo de una vida digna, recurriendo a la emigración para conseguirla, hay también otras motivaciones, como la de liberarse de un trabajo necesariamente incómodo, al que los poderes públicos vienen prestando muy poca atención. De todas formas sigue en pie lo que planteaba Jovellanos: "En algunos concejos de Asturias sobran muchos brazos, y ya la agricultura no puede ocuparlos". Las estadísticas más recientes y más fiables dan todavía una población campesina en Asturias superior al $18 \%$, aunque habría que matizar bastante, ya que muchos son campesinos como segunda ocupación. De todas formas es un porcentaje muy superior a la media de los países de la Comunidad Económica Europea. La conclusión está clara: como la tierra es prácticamente la misma, aunque se la pueda mejorar y se puedan perfeccionar las técnicas de cultivo, el producto de la tierra varía poco y su rentabilidad se relaciona fundamentalmente con la evolución de los precios. Está, pues, claro que la renta del campesino, agricultor o ganadero, está en proporción a la extensión de tierra utilizable, y por lo tanto, a la existencia de sólo aquellos agricultores o ganaderos que puedan subsistir dignamente. Merece la pena repetir las palabras de Jovellanos: "trabajar mucho, comer poco y vestir mal es un estado de violencia que no puede durar". Quiero subrayar la expresión "estado de violencia". El hombre puede estar sometido a muchos estados de violencia, desde el de una ley injusta hasta el de un grupo dominante; pero es indudable que una violencia mucho peor es la del que se encuentra en una situación

4 Cartas del viaje de Asturias (Cartas a Ponz), ed., pról. y notas de José Miguel Caso González, Ayalga Ediciones, Salinas, 1981, t. 1, pp. 155-156.

5 Cartas. . ., t. 1, pp. 156-157. 
económica como la que Jovellanos describe, una situación que no puede durar, por lo que el que la padece tratará de buscar una solución, y la que está más al alcance de su mano es la emigración.

Pero este estado de violencia del campesinado tiene otra vertiente implícita en las palabras de Jovellanos, y denunciada por él en la Carta sexta de las del Viaje de Asturias y en el Informe en el expediente de Ley Agraria. Estaba precisamente en el hecho de que la mayor parte de los campesinos fueran colonos y no propietarios, y en que no podían tampoco ser propietarios, por estar muchas fincas vinculadas o en manos muertas, haber por lo tanto muy escasa circulación de tierras, y en consecuencia de ello, a precios astronómicos. Los únicos que compraban lo poco que se ponía en venta, en su mayor parte bienes no pertenecientes ni a la iglesia ni a la nobleza, eran los escasos comerciantes que se enriquecían y los pocos indianos que volvían con abundantes pesos; pero lógicamente compraban caro y como no explotaban directamente la tierra, el colono seguía siendo colono. Unido esto al minifundio está claro que el campesinado era pobre, que tenía que trabajar mucho y vender como podía lo poco que podía vender (generalmente era trueque), cuando necesitaba algo. Menos mal que al propietario las rentas se le pagaban en frutos, aunque a veces era un tanto por ciento muy elevado de la cosecha conseguida, especialmente en los años malos. Jovellanos clama por la desamortización y por una política, sobre la base de créditos o ayudas públicas, que permita al colono y al jornalero acceder a la oropiedad de las fincas.

Pero si éste era un paso previo para la salvación del campesinado, no era la solución al problema de los brazos sobrantes. Ante todo Jovellanos pide una ley que señale un límite al minifundio, como también al latifundio andaluz. Tenía que ser una ley en la que

no sólo se tenga cuenta de lo necesario, sino también de aquellas comodidades sin las cuales es intolerable el trabajo y amarga la vida; no señalándose suerte alguna que no pueda dar al colono por fruto de su trabajo una subsistencia cómoda y segura.

Esta operación, amigo mío, tendría muy provechosas consecuencias: mejoraría desde luego la condición de nuestros labradores; fijaría su número y su cómoda subsistencia; señalaría los brazos que debían volverse a otras profesiones, y facilitaría maravillosamente los establecimientos de industria. Todo clama por una providencia tan saludable; pero singularmente la naturaleza misma del cultivo a que está dedicada esta porción estimable de nuestro pueblo ${ }^{6}$.

Por lo tanto, Jovellanos plantea una remodelación del campo, que abarca dos aspectos: libre circulación de las tierras, con el paso del colono a propietario, y la acumulación de bienes en cada familia, para hacer rentable su explotación.

6 Ibid., pp. 157-158. 
¿Y los brazos que sobran? Naturalmente, Jovellanos no sólo no descarta la emigración, que a él le parece bien, como veremos después, sino que piensa en otra emigración, la del campo a nuevos lugares de trabajo. Los puestos de trabajo en la industria eran para Jovellanos la solución ideal al problema del campesinado asturiano. Pero en Asturias no había prácticamente industria, a pesar de ser una región privilegiada, que podía abrir múltiples cauces a la creación de puestos de trabajo. Jovellanos analiza tres tipos de industria, a los que él llama rústica, popular y la que sirve inmediatamente al lujo. La primera y la última tienen relación directa con el problema de la emigración.

La industria rústica es la que utiliza como materia prima los productos agrícolas, ganaderos y pesqueros. Algunos derivados lácteos asturianos son excelentes, pero no se ha sabido prepararlos para que duren, como quesos y mantecas extranjeros, que se venden en Madrid al doble de precio; nada se sabe en Asturias de la industria de la salazón de carnes y pescados; nada de reducir a pasas y confituras nuestras riquísimas frutas; nada de aprovechar otros frutos para la fabricación de aceites de uso en farmacia, en la pintura y en varias artes; hasta no se sabe fabricar la excelente sidra de manera que dure y resista el transporte. Esto es lo que opina Jovellanos.

La industria en la que fundamentalmente piensa don Gaspar es "aquella que sirve inmediatamente al lujo, que se ocupa en dar alimento al comercio, que ofrece útil empleo a un increíble número de manos, y que, finalmente, produce inmensas riquezas por representación de su trabajo". Jovellanos reconoce que esta industria no existe en Asturias, a pesar de que la región dispone de materias primas y de mano de obra abundante. Para don Gaspar esta carencia de industria de consumo obedece a la falta de conocimientos, a la escasez de capitales y a otras causas, hijas de las antecedentes:

Las demás causas que retardan el progreso de la industria son hijas de las antecedentes. La pereza, que no se mueve sino a la vista de grandes y evidentes estímulos; la preocupación, que grita contra todo lo nuevo porque no lo conoce, y que prefiere una ignorancia que la lisonjee a una ilustración que la acusa; la envidia, que nada deja crecer ni madurar, y que lucha continuamente por sofocar en la cuna todos los establecimientos que pueden hacer la fortuna de su vecino, y sobre todo una cierta indolencia con que algunas gentes, que tienen aquí como en otras partes la primera influencia, miran todos los medios de hacer el bien que no están fiados a su mano, y sacrifican la felicidad común al interés de su clase, son sin duda causas muy ciertas, aunque parciales, de este atraso. Pero reflexione usted que la principal nace de la ignorancia, y por lo menos es incompatible con la verdadera ilustración ${ }^{7}$.

Para insistir en la falta de ilustración cita el discurso de un "ilustre

7 Ibid., t. 2, pp. 16-17. 
patricio", que no puede ser otro que el que él mismo pronunció en la Sociedad Económica de Oviedo en mayo de $1782^{8}$. Pero añade esta triste observación: "Es verdad que este misionero ha hecho poco fruto entre sus paisanos".

La relación entre esta industria de consumo y los brazos sobrantes del campo la expresa así Jovellanos;

$\mathrm{Ni}$ crea usted que he dicho estas cosas por meterme a declamador; las digo únicamente porque me duele mucho ver tantas ventajas desconocidas, tantas proporciones malogradas y tantos bienes miserablemente menospreciados y perdidos. Esta superabundancia de población clama por el establecimiento de muchos nuevos ramos de industria, no ya para buscar la riqueza, que es efecto suyo, sino para fijar tanto número de familias sobrantes y desacomodadas como produce esta provincia aplicada y laboriosa. En otras partes se trata de fomentar la industria para aumentar la población; aquí se la debe fomentar para no disminuirla. En otras partes se buscan por medio de la industria la riqueza y la felicidad de los pueblos; aquí se debe evitar por medio de ella su infelicidad y su ruina ${ }^{9}$.

Si Jovellanos pensaba que los brazos sobrantes del campo podrían ocuparse en estas industrias, provocando una emigración interna, el problema estaba en que, ante una situación indudablemente grave y que exigía remedios urgentes, una planificación industrial como la que él planteaba no resolvía nada a corto plazo. Por lo tanto, era necesaria la emigración a otras provincias.

Aunque el párrafo va a ser un poco largo, merece la pena escuchar a Jovellanos:

Yo miro estas colonias emigrantes que pasan los montes y se derraman a buscar su vida por toda la Península, como una exacta medida del sobrante de su población. Váyalos usted examinando uno a uno, y hallará que no hay entre ellos quien abandone una subsistencia segura en su país por buscar fuera de él una subsistencia arriesgada e incierta. Todos pasan a buscar fuera de aquí una ocupación de temporada en que puedan ganar lo necesario para subsistir y mantener una familia dentro de su misma patria, o bien a buscar una subsistencia más durable, que sólo encuentran fuera de ella, pero sin perder jamás de vista el designio de volver a disfrutar en sus hogares la fortuna que se hayan labrado en otra parte.

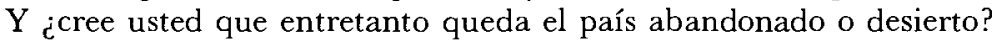
$¿ \mathrm{O}$ que sus campos desamparados por los colonos quedan yermos y sin cultivo? Nada menos. Los que pasan allá, o no tienen casería, o la tienen de tan corta extensión y producto, que no necesitando del trabajo del colono por todo el año, le permiten que vaya a llevar una parte de él a otra provincia, y a feriar por este medio lo que le falta para sustentar su fami-

${ }^{8}$ Discurso pronunciado en la Sociedad de Amigos del País de Asturias, sobre la necesidad de cultivar en el Principado el estudio de las Ciencias Naturales, incluido por Nocedal en $B A E$, 46, pp. 302-304, y que había sido editado en Oviedo en 1782.

9 Cartas. .., t. 2, p. 18. 
lia. Así se nota lo primero, que la mayor parte de los que van a residir por allá son de aquellos concejos donde, destinadas muchas tierras a pastos y prados para la cría y granjería de mulas y otros ganados, quedan menos tierras laborables, menos número de caserías, y por consiguiente menos proporción para aumentar el acomodo de nuevas familias. Note usted lo segundo, que si de estos y otros concejos vienen algunos vecinos de aqueIlos que tienen a su cargo alguna renta, su venida es siempre a trabajar en la siega u otra faena de temporada en los campos de Castilla, y volverse luego a mantener el resto del año su familia con el fruto de su sudor y trabajo. Note usted lo tercero, que los que permanecen allá por más largo tiempo no tienen por lo común otra ambición que la de juntar algún caudalillo para volverse a su casa, comprar alguna tierra, algún ganado, y proporcionar así un establecimiento en que puedan mantener su familia. Todo lo cual prueba a mi ver concluyentcmente que estos emigrantes no abandonarían su país si hubieran hallado en él una subsistencia segura, y que por lo mismo deben mirarse como el sobrante de su población.

Muchas veces he admirado como un error en que han caído aun las gentes más cuerdas y avisadas de este país, el lastimarse de tales emigraciones como de un mal grave y digno de remedio, y más aun que se tratase seriamente de buscar alguno que las disminuyese o evitase del todo. Porque ¿qué sería del resto de la población si en el estado actual se lograse retener dentro del país estos individuos que ya no caben en él? ¿ Es posible que no se vea que, reducidos a vivir donde ni la agricultura ni la industria les ofrecen ocupación ni subsistencia, o perecerían de necesidad, u obligados a subsistir del producto del trabajo ajeno, menguarían el bienestar y la fortuna de las demás familias laboriosas? ${ }^{10}$

En estos párrafos hay una clara referencia a la actitud de muchos eclesiásticos de la época, y creo que también a un curioso episodio, cuyo expediente se conserva en el Archivo Histórico Nacional, Consejos, leg. 778, relacionado con la emigración a Castilla de los hombres del concejo de Salas.

El cura de Priero, Antonio Martínez, envió el 23 de enero de 1782 una representación a la Sociedad Económica de Amigos del País de Asturias, en la que exponía los perjuicios que causaba a la agricultura, en los concejos de Valdés y Salas, el que los mozos, recién casados, abandonaran sus haciendas y a sus mujeres para irse a Castilla. No se dice a qué tipo de trabajos se dedicaban, pero el buen cura insiste en que allá se acostumbran a la holgazanería y al vicio, sobre todo al del vino. El cura dice que ellos argumentan que lo hacen por necesidad extremada: "Necesitamos desempeñar nuestras haciendas, y sin que traigamos cuatro reales no podemos librarnos de miseria". Pero esto es una disculpa, porque en realidad sólo les mueve el mal ejemplo de otros que les han precedido, sin que hagan caso de las exhortaciones y los consejos de los celosos párracos. Los únicos ricos son ciertamente los que se quedan. Además el daño que una ausencia de tres, seis o más años cau-

10 Ibid., pp. 19-21. 
sa es incalculable, tan sólo con pensar en los hijos que no nacen. Y para colmo, a la vuelta ya no quieren trabajar, acostumbrados como están a la holganza.

El cura de Priero tenía indudablemente una visión del problema excesivamente corta, por no decir económicamente interesada. Cerca le andaba la Sociedad, que estudia este escrito y considera que "ha sido continuo y universal el clamor de todos los celosos del bien de las almas y de la felicidad del país" por "poner remedio a este desorden, pero no se le ha encontrado solución". Una muy eficaz sería que se "prohibiese a todo casado salir sin pasaporte del juez, dado con tiempo limitado. . . y con preciso informe del párroco"; pero lo mejor es que Campomanes lo arregle.

Campomanes, sin embargo, no vio nada clara la cuestión, ya que además "se tiene entendido que en Salas se han aplicado algunos terrenos cultivables a prados para la cría de mulas de algún tiempo a esta parte, y pueden mediar otras causas en los referidos concejos que produzcan la emigración". En consecuencia, pide datos e informes; pero, por desgracia, no queda constancia en el legajo $778 \mathrm{ni}$ de los informes pedidos a la Sociedad, al regente y al obispo, ni de la decisión adoptada, si es que se tomó alguna.

Merece la pena subrayar que este episodio se produce poco antes de que Jovellanos hable en mayo de 1782 en la Sociedad, y de que ésta le elija su Director.

El episodio me parece auténticamente triste, porque demuestra una total y absoluta incomprensión por parte del cura de Priero, pero también por parte de los miembros de la Sociedad Económica de Asturias, llamada precisamente a planificar de algún modo la posibilidad del desarrollo económico de la región, pero que, en manos fundamentalmente de eclesiásticos, nobles y pequeños burgueses ovetenses, fue incapaz de ir más allá de un paternalismo inútil para remodelar todo el panorama económico asturiano, que era lo que Jovellanos les pedía en su discurso de mayo.

Pero si al cura de Priero y a los miembros de la Sociedad Económica les preocupaba más que la vida digna del campesino el asegurar sus rentas, no les iban a la zaga los diputados de la Junta General del Principado, que aprueban el 26 de agosto de 1781 unas nuevas Ordenanzas, en las que el art. 78 del título XI se lee:

Por el atraso que padece la agricultura con la frecuente salida de los naturales, estableciéndose por años y temporadas fuera de sus lugares y aun del Principado, se prohíbe que pueda hacerlo alguno por más de 20 días, no siendo con licencia de la Justicia, que no la podrá dar sin informe de la Junta de Agricultura de la Parroquia [organismo creado por estas mismas Ordenanzas], así sobre la causa de la salida, como de quedar en casa del que lo solicita persona hábil para el cultivo de las tierras y cuidado de los ganados; pues no siendo según este informe justa la causa de 
la ausencia, no podrá concederse la licencia, ni aun siéndolo, sin que quede en casa persona o propósito y capaz para el cultivo y cuidado de tierras $y \operatorname{ganados}^{11}$.

En este ambiente se entiende muy bien el valiente alegato de Jovellanos, a quien ante todo preocupa el bienestar de los campesinos. Pero don Gaspar defiende la emigración desde otra perspectiva, la de la riqueza que entra en Asturias gracias a ella. Dice así Jovellanos:

No sólo es un error el empeño de reducir las emigraciones con respecto a los mismos emigrantes, sino que lo es también con respecto a todo el país. Las gruesas sumas que traen o envían a él, ganadas en otras provincias, aumentan considerablemente su riqueza, y aunque no son fáciles de reducir a cálculo, no por eso deben ser un objeto de nuestro desprecio o nuestro olvido ${ }^{12}$.

Jovellanos no sabía cuál era la riqueza que los emigrantes devolvían a Asturias; pero había algo que le molestaba muy profundamente y era que el indiano que volvía cargado de dinero no hiciera absolutamente nada por la creación de puestos de trabajo. Creo que el texto merece la pena transcribirlo:

Son muy frecuentes en este país las transmigraciones a América, y aunque no lo son tanto las fortunas hechas allá, no es raro que entre un centenar de hombres que perecen de miseria en aquel continente, vuelvan de tiempo en tiempo dos o tres indianos cargados de oro a perpetuar el mal con el funesto ejemplo de su fortuna.

Todo el mundo los observa y los admira. Su vajilla, sus alhajas, sus dádivas a los templos, sus socorros y regalos a la parentela, su ostentación y el crédito de su opulencia, siempre aumentados y difundidos por la opinión hasta los últimos rincones, ofrecen en este país laborioso y sencillo un espectáculo que deslumbra, y cuya triste influencia no puede esconderse a la reflexión del patriotismo.

El primer objeto de estos indianos es arraigarse comprando tierras, labrando casas, fundando patrimonio y ligando a una vinculación perpetua los frutos y su trabajo ${ }^{13}$.

Dicho de otra manera: indianos con mucho oro y más fachenda, pero totalmente inútiles al progreso de la región. ¿Acaso no nos quedan todavía ejemplos de estos emigrantes?

Para terminar, se puede resumir el pensamiento de Jovellanos sobre la emigración asturiana en los siguientes puntos: hay que remode-

11 Ordenanzas para govierno de la Junta General de el Principado y su Diputación y las generales, judiciales y políticas para la administración de justicia de todos los concejos, cotos y jurisdicciones de él. Año de M.D.CC. LXXXII. En la oficina de Asturias, p. 87.

12 Cartas. .., t. 2, p. 22.

13 Ibid., t. 1, pp. 146-147. 
lar el campo, dejando en él sólo a los que puedan obtener una adecuada renta con su explotación; hay que poner ésta a su vez en relación con una industria agrícola todavía hoy inexistente; ésta y la industria de consumo deben absorber la mayor parte de los brazos sobrantes del campo; además de esta emigración interna hay que contar con otra emigración a otras provincias españolas; estos emigrantes aportan una gran riqueza, que es necesario invertir. De esta forma queda completo el plan de reforma económica que Jovellanos piensa para su amada Asturias.

José Miguel Caso González 